\title{
Why Patient Centered Care Coordination Is Important in Developing Countries?
}

\section{Contribution of the IMIA Health Informatics for Development Working Group}

C. Otero ${ }^{1,2}$, D. Luna, ${ }^{2}$ A. Marcelo ${ }^{3}$, M. Househ ${ }^{4}$, H. Mandirola ${ }^{2}$, W. Curioso ${ }^{5}$, P. Pazos ${ }^{6}$, C. Villalba ${ }^{7}$

1 IMIA Health Informatics for Development Working Group Chair, Hospital Italiano de Buenos Aires, Argentina

2 Health Information Department, Hospital Italiano de Buenos Aires, Argentina

3 IMIA Health Informatics for Development Working Group Co-Chair, National Telehealth Center, University of the Philippines Manila, Philippines

${ }^{4}$ College of Public Health and Health Informatics, King Saud Bin Abdulaziz University for Health Sciences, Riyadh, Saudi Arabia

5 Dirección de Evaluación y Gestión del Conocimiento. Consejo Nacional de Ciencia, Tecnología e Innovación Tecnológica (CONCYTEC), Presidencia del Consejo de Ministros, Lima, Perú

${ }^{6}$ Cabolabs, Montevieo, Uruguay

7 Facultad Politécnica, Universidad Nacional de Asunción, Paraguay

\section{Introduction}

Even when definitions about what is Patient Centered Care coordination (PCCC) are not strict, there is no doubt that focus on this model of care could result in benefit for patients, their families and, also, for the health system. The Institute of medicine (IOM) in the USA define PCCC as: "health care that establishes a partnership among practitioners, patients, and their families, to ensure that decisions respect patients' needs and preferences, and that patients have the education and support they need to make decisions and participate in their own care" [1]. This implies a set of systematic activities designed to satisfy the needs of patients for wellness and good health [2]. It means making resources available to patients to enable them to make the right decisions about their healthcare [3-5]. These resources are mostly information (to support personal decision making), but may also be appropriate medical technologies and therapies $[6,7]$. In this sense, Information technologies (IT) could improve the access to this kind of care, and could have the potential to improve access to and quality of health care [7-10].

Although benefits such as improved patient satisfaction, quality of care, and health outcomes, while at the same time reducing health care costs and disparities in health care, have been demonstrated in developed countries [5, 7, 11-15], specific situations in developing countries, ranging from literacy to political instability, make the development of PCCC more difficult [10, 16-20]. Knowing that developing countries face multiple difficulties in relation to access to health for all the people, disparities in the access to health, but also disparities in the quality of services, and considering the difficulties in developing programs patient-centered, their families and the coordination and integration with the health care deliverers, models like PCCC, which focus on the optimization of resource use, and promotion of patients' rights and high quality health services, could address, in part, some of these problems.

The IMIA working group Health Informatics for Development has been working in the development and the spread of Medical Informatics. PCCC is also considered one of the main topics to work for the next two years, considering the impact that information technology (IT) could have in this field. This is a position paper for the working group, which initiates with this work a more comprehensive project. More information about the whole project, the activities of the group and other publications are available at the working group website.

In this paper we analyze the benefits that PCCC could bring to developing countries; and identify the barriers and propose strategies to reach this model of care for our countries.

\footnotetext{
* http://www.imia-medinfo.org/new2/ node/ 140
} 


\section{Methods}

Discussions about Patient Centered Care Coordination were initiated among the participants in the IMIA working group Health Informatics for Development sessions held during MEDINFO 2013 in Copenhagen, Denmark and INFOLAC 2014 in Montevideo, Uruguay. This debate emerged from a brief guide that posed answers to the following questions:

- What is Patient Centered Care Coordination for you?

- Why do you consider Patient Centered Care Coordination important for developing countries?

- Do you know any barriers to grow in this direction in your region?

- What guidelines, papers or other resources do you consider relevant in the topic?

After this discussion, results were organized in order to be published and an additional bibliographic search was conducted, following the recommendations in answer to the last question, to add relevance to the participants' impressions.

\section{Results}

Following the experiences shared in our discussion and reviewing some developed country publications, we found that Patient Centered Care Coordination (PCCC) encompasses a broad definition: PCCC is a model of health care that allows for a holistic view on patient care, and evaluating the patient as a whole, not just parts of it like medical specialists do [9, 11, 21-24]. This view includes physical care, mental care, socio-environmental care, and self care. To implement this we need the specification of that model, including processes, the necessary roles in the healthcare team, tools that allow planning and evaluation of the patient's health and tools to coordinate the health care team [25-28]. The main factor that makes PCCC viable is the communication between the health care team members, and the coordination of that team with the patient and his/her environment (family, friends, etc.) [2, 28-31]. Active participation of the patients and his environment is needed to support this coordination, and countries should provide tools to make this coordination effective, because it traverses different health care institutions and professionals [2, 3, 17-19].

The potential implementation of this model of care in developing countries is particularly interesting because the health system becomes more efficient when it focuses on the person, not the disease.

As some studies demonstrate in developed countries, this care model can be cost effective $[14,15]$, because PCCC responds directly to the health needs of the patient/person even before they get sick. For developing countries, this can result in tremendous savings compared to expenses incurred with treatment or curative methods. This model could also require fewer medical technological resources. Focus on prevention, more than on diseases, could be an interesting point of view from which to optimize the investment in IT, with the focus on managing the PCCC programs more than on incorporating medical technology [7, 8, 18, 19].

Involving the patients and their families in the care process [17, 26, 28, 30, 31], allows not only the management of their diseases, empowering them in their own care, but also, increases the level of satisfaction in their case $[5,22,26,32,33]$. A customized program of delivering information and providing feedback can help patients/ persons manage their own health. PCCC is a powerful and empowering concept and turns the table around making the patients responsible for their own health (by the lifestyles they adopt) rather than having them only depend on healthcare professionals for all their health needs [27].

If we know PCCC could improve the health care quality, and reach a high quality of care: Why is so difficult to grow in this direction in developing countries?

In these countries the lack of a comprehensive and integrated primary healthcare network, which is the backbone of patient centered care, is one of the main barriers to reach this objective. The political instability and the lack of transparency in management of resources in many countries could be also considered a barrier [17, 19]. Programs like PCCC, even with a focus on patients, could be considered as "a control" for public resources, and could increase resistance to the development and implementation of this kind of care models.

Information technology infrastructure is also important, especially in remote areas or large territories, but also in home care, where there will be a lack of information technology infrastructure to coordinate with patients and providers. In urban settings, costs of setting up a network with high internet speeds may be challenging for some segments of the population thus limiting patient centered care to the more affluent people in the developing world [10,34,35].

Culture is also a challenging barrier. To overcome years of tradition that identify the high complexity hospital with the maximum standard of care, and re-educate patients to access health care from community primary care centers can even take generations before achieving the goal. Decentralization of care and integrating it into coordinated networks can be one of the biggest barriers to break down $[5,12,16,18,28]$.

Also, there is a lack of integration in the healthcare system between primary, secondary and tertiary care. For patient centered care to work there has to be co-ordination between the variety of public and private hospital system at the primary, secondary, and tertiary levels. A need for a health information exchange to monitor the progress and success of patients as they use multiple entry points within the system is also considered an obstacle to reach a real PCCC $[29,36,37]$.

Patient e-health literacy is a problem as well. Much of the developing world is not health literate. Explaining and shifting attitudes about the patient centered care may be a problem as well as people are so used to coming to the hospital or clinic for care $[7,17]$.

Economic interests and the pharmaceutical and medical technology industry pressure are a barrier, any new model that could modify interests of these industries could be considered a barrier, taking account the pressure that they could apply against not only hospitals, but also governments [18].

Considering this challenging problematic, we propose some initiatives that could improve the situation, and help to achieve PCCC in developing countries: 
Working hard to reach strong health policies, focus on patients more than diseases, avoiding vested interests and fighting to optimize the use of resources could improve the performance in the devolvement of PCCC programs. International collaboration, between countries, but also between institutions or international associations that lead this process could bring benefits.

We believe information technology, perhaps also mobile technologies, will play an important role in patient centered care coordination. In some countries in the developing world there are more phones than people [7, 38, 39]. Mobile phones provide direct access to the patients, especially, in low-income developing countries; SMS technologies will play an important role in coordination of patient centered care. New methods of interacting, education, and monitoring are needed to establish a system of patient centered care, and IT could help to meet the goals in this direction. In the same way, the Personal Health Record (PHR) could be an excellent tool to help us in the adoption of this approach, because the patients can consult their records and also, can contribute to them by adding useful data/information about their health. The PHR could also be used as a good communication channel between both physicians and patients.

It is important to consider IT as the tool, not the goal. It should be at the services of the program, and be implemented as needed. If this approach is not followed, the use of IT could increase the cost and not necessarily improve the outcomes.

Education should be the first step in the development of PCCC programs. Training process for governmental deciders, health care team and patients could help spread this initiative, and reach the goal of PCCC in developing countries.

PCCC is important, since each person has unique care needs, and personalized care seems to be the next health care paradigm. In developing countries we are far from implementing this because of the lack of defined processes and tools. We also need a change in the medical culture, going from each doctor working alone and evaluating just one aspect of the patient, to having a coordinated team working together, reviewing each patient's health status, with continuous planning, evaluation and control. Doctors will need to work together with other professionals, technicians' ancillary health workers, patients and their families, and governments will be required to provide the context and the tools to achieve PCCC.

\section{Discussion}

Considering that PCCC could improve the quality of care, patients and families satisfaction and optimize the use of resources, thus reducing health care costs and disparities in health care, its implementation in developing countries can have a positive impact. Problems and disparities in these countries could be reduced if governments, helped by other developed countries and international associations related with the topic, work together to reach this goal. Initiatives which focus on education, IT, policies and cultural issues will be necessary to spread this health care model in the developing world. Patients as the center of the care process, and the health care team working together with them and their families will have a positive outcome in these countries.

We believe that sharing our positive opinions, and the good and great impact that PCCC could have in the developing world should be interesting for others. Even more, we think that sharing this thinking could help us to get collaborative partners to disseminate this health care model in our countries.

This work is the first step in a more extensive project at the IMIA working group Health Informatics for Development. Several limitations ranging from the non formal qualitative analysis of the group discussion, plus the partial and non-systematic review of the literature reflected in the bibliography must be considered when you read this paper.

\section{Conclusion}

PCCC in developing countries has the potential to improve quality of care, and patient and family satisfaction, while reducing disparities and costs. Without doubt, and especially in developing countries, these outcomes will be positive for the health system, but also for the patients. Education, IT developments, policies and cultural issues must be addressed in an international collaborative context in order to reach this goal.

\section{Acknowledgement}

Our special thanks to Patricia Yao, from Oregon Health \& Science University (OHSU) for her help and support reviewing the language and rammatical in this paper.

\section{References}

1. Institute of Medicine. Crossing the Quality Chasm: A New Health System for the 21st Century, Vol. 6. Washington, DC: National Academy Press; 2001.

2. Suchman AL. Understanding and Promoting Patient-Centered Care. N Engl J Med 1994 Mar 24;330(12):873.

3. Epstein RM, Fiscella K, Lesser CS, Stange KC. Why The Nation Needs A Policy Push On Patient-Centered Health Care. Health Aff(Millwood) 2010 Aug 1;29(8):1489-95.

4. Coordinated Care pcmh.ahrq.gov [Internet]. [cited 2015 Jan 9]. Available from: http://www.pcmh. ahrq.gov/page/coordinated-care

5. Little P, Everitt H, Williamson I, Warner G, Moore $\mathrm{M}$, Gould C, et al. Observational study of effect of patient centredness and positive approach on outcomes of general practice consultations. BMJ 2001 Oct 20;323(7318):908-11.

6. Mirzaei M, Aspin C, Essue B, Jeon Y-H, Dugdale P, Usherwood T, et al. A patient-centred approach to health service delivery: improving health outcomes for people with chronic illness. BMC Health Serv Res 2013 Jul 3;13(1):251.

7. Davis K, Schoenbaum SC, Audet A-M. A 2020 vision of patient-centered primary care. J Gen Intern Med 2005 Oct;20(10):953-7.

8. O'Malley AS, Grossman JM, Cohen GR, Kemper NM, Pham HH. Are Electronic Medical Records Helpful for Care Coordination? Experiences of Physician Practices. J Gen Intern Med 2010 Mar 1;25(3):177-85.

9. Lawrence M, Kinn S. Defining and measuring patient-centred care: an example from a mixed-methods systematic review of the stroke literature. Health Expect Int J Public Particip Health Care Health Policy 2012 Sep;15(3):295-326.

10. CEPAL. Manual de salud electrónica para directivos de servicios y sistemas de salud [Guide for electronic health service managers and health systems][Internet]. 2014 [cited 2015 Jan 9]. Available from: http://www.cepal.org/es/publicaciones/manual-de-salud-electronica-para-directivos-de-servicios-y-sistemas-de-salud

11. Crossing the Quality Chasm: A New Health System for the 21 st Century [Internet]. [cited 2015 Jan 9]. Available from: /catalog/10027/crossingthe-quality-chasm-a-new-health-system-for-the

12. Kellerman R, Kirk L. Principles of the pa- 
tient-centered medical home. Am Fam Physician 2007 Sep 15;76(6):774-5.

13. Rosenthal TC. The medical home: growing evidence to support a new approach to primary care. J Am Board Fam Med JABFM 2008 Oct;21(5):427-40.

14. M Stewart JBB. The impact of patient-centered care on outcomes. J Fam Pract 2000;49(9):796-804.

15. Mead N, Bower P. Patient-centred consultations and outcomes in primary care: a review of the literature. Patient Educ Couns 2002 Sep;48(1):51-61.

16. Mahendradhata Y, Souares A, Phalkey R, Sauerborn R. Optimizing patient-centeredness in the transitions of healthcare systems in low- and middle-income countries. BMC Health Serv Res 2014 Sep 12;14(1):386.

17. CEPAL. Población y salud en América Latina y el Caribe: retos pendientes y nuevos desafíos. [Population and health in Latin America and the Caribbean: outstanding matters, new challenges] [Internet]. 2014 [cited 2015 Jan 9]. Available from: http://www.cepal.org/es/publicaciones/ poblacion-y-salud-en-america-latina-y-el-caribe-retos-pendientes-y-nuevos-desafios

18. CEPAL. Salud electrónica en América Latina y el Caribe: avances y desafíos. [E-Health in Latin America and the Caribbean: progress and challenges] [Internet]. 2014 [cited 2015 Jan 9]. Available from: http://www.cepal.org/es/publicaciones/ salud-electronica-en-america-latina-y-el-caribe-avances-y-desafios

19. Ruelas E, Gómez-Dantés O, Leatherman S, Fortune T, Gay-Molina JG. Strengthening the quality agenda in health care in low- and middle-income countries: questions to consider. Int J Qual Health Care J Int Soc Qual Health Care ISQua 2012 Dec;24(6):553-7.

20. WHO | Urban Health Equity Assessment and Response Tool (Urban HEART) [Internet]. WHO. [cited 2015 Jan 9]. Available from: http://www. who.int/kobe centre/measuring/urbanheart/en/

21. Bergeson SC, Dean JD. A systems approach to patient-centered care. JAMA. 2006 Dec 20;296(23):2848-51.
22. Impact of Relational Coordination on Quality of Care, Pos Postoperative Pain and Functioning, and Length of Stay: A Nine-Hospital Study of Surgical Patients. Medical Care 2000;38(8):80719 [Internet]. [cited 2015 Jan 9]. Available from: http://journals.lww.com/lww-medicalcare/Fulltext/2000/08000/Impact_of_Relational_Coordination_on_Quality_of.5.aspx

23. Reynolds A. Patient-centered Care. Radiol Technol 2009 Dec;81(2):133-47.

24. Patient Centered Coordinated Care [Internet]. [cited 2015 Jan 9]. Available from: http://www. commonwealthfund.org/grants-and-fellowships/ programs/archived-programs/patient-centered-coordinated-care

25. Dwamena F, Holmes-Rovner M, Gaulden CM, Jorgenson S, Sadigh G, Sikorskii A, et al. Interventions for providers to promote a patient-centred approach in clinical consultations. Cochrane Database Syst Rev 2012;12:CD003267.

26. Fiscella K, Meldrum S, Franks P, Shields CG, Duberstein P, McDaniel SH, et al. Patient trust: is it related to patient-centered behavior of primary care physicians? Med Care 2004 Nov;42(11):1049-55.

27. Haidet P, Fecile ML, West HF, Teal CR. Reconsidering the team concept: educational implications for patient-centered cancer care. Patient Educ Couns. 2009 Dec;77(3):450-5.

28. Mauksch LB, Dugdale DC, Dodson S, Epstein R. Relationship, communication, and efficiency in the medical encounter: creating a clinical model from a literature review. Arch Intern Med. 2008 Jul 14;168(13):1387-95.

29. Dale J, Sandhu H, Lall R, Glucksman E. The patient, the doctor and the emergency department: a cross-sectional study of patient-centredness in 1990 and 2005. Patient Educ Couns. 2008 Aug;72(2):320-9.

30. Shields L, Pratt J, Hunter J. Family centred care: a review of qualitative studies. J Clin Nurs. 2006 Oct;15(10):1317-23.

31. Shields L, Zhou H, Pratt J, Taylor M, Hunter J, Pascoe E. Family-centred care for hospitalised children aged 0-12 years. Cochrane Database Syst
Rev. 2012;10:CD004811.

32. Wagner EH, Groves T. Care for chronic diseases. BMJ. 2002 Oct 26;325(7370):913-4.

33. Patient-Centered Communication in Cancer Care: Promoting Healing and Reducing Suffering [Internet]. [cited 2015 Jan 9]. Available from: http:// appliedresearch.cancer.gov/areas/pcc/communication/monograph.html

34. Stender SC, Christensen A. Patient-centered primary health care: synergy potential for health systems strengthening. Int J Tuberc Lung Dis Off J Int Union Tuberc Lung Dis. 2013 Oct;17(10 Suppl 1):15-21.

35. Bates DW, Bitton A. The Future Of Health Information Technology In The Patient-Centered Medical Home. Health Aff (Millwood). $2010 \mathrm{Apr}$ 1;29(4):614-21.

36. Pham HH, O'Malley AS, Bach PB, Saiontz-Martinez C, Schrag D. Primary Care Physicians' Links to Other Physicians Through Medicare Patients: The Scope of Care Coordination. Ann Intern Med. 2009 Feb 17;150(4):236-42.

37. Berendes S, Heywood P, Oliver S, Garner P. Quality of Private and Public Ambulatory Health Care in Low and Middle Income Countries: Systematic Review of Comparative Studies. PLoS Med. 2011 Apr 12;8(4):e1000433.

38. De Jongh T, Gurol-Urganci I, Vodopivec-Jamsek V, Car J, Atun R. Mobile phone messaging for facilitating self-management of long-term illnesses. Cochrane Database Syst Rev. 2012;12:CD007459.

39. Vodopivec-Jamsek V, de Jongh T, Gurol-Urganci I, Atun R, Car J. Mobile phone messaging for preventive health care. Cochrane Database Syst Rev. 2012;12:CD007457.

\section{Correspondence to:}

Dr. Carlos Martín Otero

Departamento de Informática en Salud

Hospital Italiano de Buenos Aires

E-mail:carlos.otero@hospitalitaliano.org.ar 